\title{
Analysis of 190 Female Patients after Appendectomy
}

\author{
Abdulrahman M. Alotaibi $\mathbb{D},{ }^{1,2}$ Leena H. Moshref $\mathbb{D}^{2},{ }^{2}$ Rana H. Moshref $\mathbb{D}{ }^{3}$ \\ and Lina S. Felemban ${ }^{3}$ \\ ${ }^{1}$ Department of Surgery, Faculty of Medicine, University of Jeddah, Jeddah, Saudi Arabia \\ ${ }^{2}$ Department of Surgery, Doctor Soliman Fakeeh Hospital, Jeddah, Saudi Arabia \\ ${ }^{3}$ Department of Surgery, National Guard Hospital, Jeddah, Saudi Arabia
}

Correspondence should be addressed to Abdulrahman M. Alotaibi; aalotaibi@uj.edu.sa

Received 9 July 2021; Revised 16 October 2021; Accepted 9 November 2021; Published 27 November 2021

Academic Editor: Yoshitsugu Chigusa

Copyright () 2021 Abdulrahman M. Alotaibi et al. This is an open access article distributed under the Creative Commons Attribution License, which permits unrestricted use, distribution, and reproduction in any medium, provided the original work is properly cited.

\begin{abstract}
This study is a retrospective cohort review carried out at a single, private tertiary center. We included 190 female patients who underwent surgery for acute appendicitis between January 2016 and December 2018. Two groups of patients were analyzed based on the pregnancy. The main outcome measures were complication rate and risk of abortion during or after surgery. Out of 190 female patients, eight of them were pregnant (4.2\%). The pregnant group more significantly underwent ultrasound investigation compared to the nonpregnant group. Complicated appendicitis present in two pregnant patients at advanced gestational age was not statistically significant from nonpregnant. Laparoscopic appendectomy was performed in 6/8 (75\%) of pregnant compared to $158 / 182(87 \%)$ in nonpregnant $(p=0.415)$. Compared to the nonpregnant, the pregnant group has a more fecolith, positive peritoneal fluid culture, and wound infection, with $E$. coli more frequently isolated in $25 \%$. None of the pregnant patients had an abortion, preterm labor, or mortality during or after surgery. In conclusion, laparoscopic appendectomy is a low-risk operation for pregnant with acute appendicitis.
\end{abstract}

\section{Introduction}

Acute appendicitis (AA) is estimated to be one of the most frequent surgical emergencies that requires urgent intervention [1]. The stated incidence ranges $28 \%, 44 \%$, and $24 \%$ in the first, second, and last trimester [2]. The clinical presentation is nonspecific, including abdominal pain, nausea, vomiting, fever, and leukocytosis, which are not helpful as predictive indices [3]. The diagnosis of AA is troublesome throughout the pregnancy due to physiological and anatomical shifts, which defer the management [4]. Early diagnosis and intervention, either surgically or by antibiotics, are vital as noncomplicated AA can rupture and lead to perinatal and maternal complications, for instance, premature delivery, miscarriage, and fetal loss [5]. This study aimed to evaluate the clinical presentation and outcome of appendectomy in pregnant and nonpregnant female patients.

\section{Materials and Methods}

This study is a retrospective review of appendectomy procedures at Dr. Soliman Fakeeh Hospital (Jeddah, Saudi Arabia). Four hundred fifty-one consecutive adult patients underwent surgery for acute appendicitis between January 2016 and December 2018. We excluded pediatric age, male patients, and appendectomy as combined with other operations. A total of 190 females were in the current study. Two groups, pregnant and nonpregnant, were diagnosed based on clinical examination, radiological imaging, and diagnostic laparoscopy. The primary outcome is the rate of 
complication, abortion, or mortality during or after appendectomy.

The Institutional Review Board of Fakeeh College for Medical Sciences (FCMS) approved the study protocol.

2.1. Surgery Techniques. Laparoscopic appendectomy is the procedure of choice in our institution to manage acute appendicitis. The decision to perform an open appendectomy or convert depends on the surgeon's preference and the patient's clinical condition.

2.2. Statistical Analyses. Fisher's exact test with two-sided verification or an unpaired Student's t-test compares the demographic and clinicopathological variables of the two groups. A $p$ value of less than 0.05 indicates statistical significance. SPSS software (version 25, SPSS Inc., Chicago, IL) analyses the data.

\section{Results and Discussion}

3.1. Characteristics of the Pregnant and Nonpregnant Group. Among the 190 females enrolled in the study, eight of them were pregnant $(4.2 \%)$. The patient's age, comorbidities, diabetes mellitus, abdominal pain duration, complicated appendicitis, appendix diameter, leukocyte count, C-reactive protein, surgical approaches, operative time, pathology finding, length of stay, and mortality were statistically insignificant among both groups (Table 1).

Compared to the nonpregnant, the pregnant group underwent more ultrasound images for evaluation (36.8 vs. $100 \%$, respectively, $p=0.001$ ) and had more positive peritoneal fluid culture ( 8.3 vs. $37 \%$, respectively, $p=0.017$ ) with E. coli and ESBL more frequently isolated.

Additionally, the wound infection rate was more significant ( 0.5 vs. $12.5 \%$, respectively, $p=0.013$ ), along with the fecolith as the cause of appendicitis (28.5 vs. $75 \%$, respectively, $p=0.011$ ).

3.2. Abortion, Mortality, and Morbidity Outcomes. In the first, second, and third trimesters, the pregnant patients were four, three, and one, respectively.

Two pregnant patients diagnosed with complicated appendicitis in the second trimester $\left(26^{\text {th }}\right.$ week) and last trimester $\left(27^{\text {th }}\right.$ week) were not significantly different from nonpregnant (25 vs. 9.5\%, $p=0.156$ ). There was no difference in appendicitis incidence concerning trimester; however, the complicated one occurred later in pregnancy.

None of the pregnant patients had an abortion, preterm labor, fetal loss, or mortality during or after surgery. During the follow-up period of the pregnancy, none of them developed any complications related to the operation-further detailed about pregnant group trimesters in Table 2.

\section{Discussion}

AA represents $65 \%$ of nontraumatic emergencies with a prevalence of 0.1 to $0.2 \%$ throughout all trimesters [6,7]. In our series, four patients out of eight were in their second trimester, similarly to others who reported the second trimester as the most frequent months to have AA [8-10]. Others stated the first trimester as the most common $[11,12]$. A Swedish study linked reduced numbers of $\mathrm{AA}$ in the $3^{\text {rd }}$ trimester to positive effects of hormones and TH1-mediated inflammatory response [13]. The majority of AA during pregnancy needs surgical intervention [14]. In agreement with others, the mean age of presentation is 31 years $[9,15]$, contrary to a younger age in China, India, and Korea [10, 16-19]. The comorbidity in some reviews affects the surgery approach, while others showed no correlation [20, 21].

The clinical and radiological evaluation of AA during pregnancy is challenging [22]. In a review of 21 pregnant, abdominal pain was higher in the first and second trimester by $57 \%$ and $23 \%$, respectively [23]. Vomiting was the most common symptom noted in other series $[9,24]$. The use of the Alvarado score in pregnancy showed positive predictive values of almost $90 \%, 80 \%$, and $75 \%$ in the first, second, and third trimester $[9,22]$. Our data observation has no statistical significance in both groups' WBC, neutrophil, and CRP levels, comparable to other reviews [7, 25, 26].

The ultrasound (US) is utilized in around $70 \%$ of pregnant compared to $30 \%$ in nonpregnant [15, 19, 27-29], which is imminent to our result (100 vs. $36 \%, p=0.001$, respectively). The US assisted in the diagnosis more in the first trimester than the last one $(p=0.004)$ with sensitivity and specificity of $80 \%$ and $92 \%$, respectively [30]. According to numerous studies, CT scan was utilized in $3 \%$ of pregnant and $15 \%$ of nonpregnant women $[10,15,28]$; however in our study, nearly $30 \%$ of nonpregnant group underwent a CT scan. Magnetic resonance imaging (MRI) is a valid and safe option to diagnose despite cost disadvantages [9, 29]. An abdominal CT might be requested when the US cannot visualize the appendix in the third trimester [11].

The rate of open appendectomy (OA) vs. laparoscopic appendectomy (LA) varies between researchers. Approximately $80 \%$ of pregnant women undergo procedures in an emergency setting, with $38.4 \%$ undergoing OA vs. $63.6 \%$ LA [16]. Others reported a high rate of OA in pregnant women, which reached $73 \%$ and $92 \%[8,19,23]$. From the New York State database which included 1000 patients, OA was performed in community centers by $50 \%$ and LA in academic centers by $60 \%$ [21]. In one tertiary hospital, the rate of LA was 1 out of 450 [31]. In our center, laparoscopy was the most used technique as it was performed in an academic hospital by $75 \%$ in pregnant and $85 \%$ in nonpregnant. Surgeon preference, as well as the gestational age, can affect the surgical approaches $[26,32]$. Conversion to open depends mainly on intraoperative findings rather than surgeon experience [24]. The incision in OA differed in the literature with $66-93 \%$ McBurney's point, $28.6 \%$ right paramedian, and $6.6 \%$ midline laparotomy $[10,11,23,33]$.

Several management strategies are in the literature. A nationwide Japanese database exhibits conservative management of AA in $67 \%$ and surgery in 33\% [29]. In a multicenter review, pregnant women were more likely to be treated with antibiotics alone $(15 \%$ vs. $4 \% ; p=0.008)$ and to have complicated appendicitis [15]. In another review of six appendectomies in pregnant women, one case complicated 
TABLE 1: Demographics and clinicopathological features of the study patients according to pregnancy status.

\begin{tabular}{|c|c|c|c|}
\hline \multirow{2}{*}{ Variables } & \multicolumn{2}{|c|}{ Values as mean \pm SD or no. of patients (\%) } & \multirow{2}{*}{$p$ value } \\
\hline & Nonpregnant group $(n=182)$ & Pregnant group $(n=8)$ & \\
\hline Age at surgery, years & $29 \pm 11.3$ & $31 \pm 4.8$ & 0.65 \\
\hline ASA score & & & 0.005 \\
\hline I & $81(44.5)$ & $1(12.5)$ & \\
\hline II & $99(54.4)$ & $6(75)$ & \\
\hline III & $1(0.55)$ & $1(12.5)$ & \\
\hline IV & $1(0.55)$ & $0(0)$ & \\
\hline Length of admission & $2.1 \pm 1.3$ & $2.3 \pm 1.0$ & 0.68 \\
\hline Diabetes & 10 & 0 & 0.64 \\
\hline Comorbidities (DM not included) & 32 & 2 & 0.43 \\
\hline \multicolumn{4}{|l|}{ Pain duration } \\
\hline Less than $24 \mathrm{~h}$ & 81 & 2 & \multirow{3}{*}{0.54} \\
\hline $24-48 \mathrm{~h}$ & 69 & 4 & \\
\hline More than $48 \mathrm{~h}$ & 31 & 2 & \\
\hline WBC $(\mathrm{u} / \mathrm{L})$ & $11.71 \pm 4.2$ & $14.51 \pm 4.2$ & 0.068 \\
\hline Neutrophil (\%) & $71.65 \pm 14.3$ & $82.36 \pm 9.2$ & 0.052 \\
\hline CRP $(\mathrm{mg} / \mathrm{L})$ & $42.51 \pm 60.9$ & $68.90 \pm 64.4$ & 0.26 \\
\hline \multicolumn{4}{|l|}{ Type of radiology study } \\
\hline Ultrasonography & 67 & 8 & \multirow[t]{2}{*}{0.001} \\
\hline CT scan & 112 & 0 & \\
\hline Appendix diameter $(\mathrm{mm})$ & $10.48 \pm 3.3$ & $10.33 \pm 1.36$ & 0.91 \\
\hline \multicolumn{4}{|l|}{ Complicated appendicitis } \\
\hline Yes & $17(9.30)$ & $2(25)$ & \multirow{2}{*}{0.18} \\
\hline No & $162(90.7)$ & $6(75)$ & \\
\hline \multicolumn{4}{|l|}{ Operative approach } \\
\hline Open & $23(12.6)$ & $2(25)$ & \multirow[t]{2}{*}{0.08} \\
\hline Laparoscopy & $158(87.4)$ & $6(75)$ & \\
\hline Operative time (min) & $48 \pm 19.6$ & $55 \pm 22.7$ & 0.33 \\
\hline \multicolumn{4}{|l|}{ Peritoneal fluid culture } \\
\hline Positive & $15(8.3)$ & $3(37.5)$ & \multirow{2}{*}{0.017} \\
\hline Negative/not done & $167(91.7)$ & $5(62.5)$ & \\
\hline \multicolumn{4}{|l|}{ Postoperative complications } \\
\hline No & $175(96.2)$ & $7(87.5)$ & \multirow{4}{*}{0.013} \\
\hline Wound infection & $1(0.5)$ & $1(12.5)$ & \\
\hline Collection & $4(2.2)$ & 0 & \\
\hline Nonsurgical & $2(1.1)$ & 0 & \\
\hline \multicolumn{4}{|l|}{ Fecolith } \\
\hline Yes & $52(28.5)$ & $6(75)$ & \multirow[t]{2}{*}{0.011} \\
\hline No & $130(71.5)$ & $2(25)$ & \\
\hline \multicolumn{4}{|l|}{ Pathology } \\
\hline No suppuration & $39(21.4)$ & $1(12.5)$ & \multirow{10}{*}{0.795} \\
\hline Acute suppuration & $123(67.6)$ & $5(62.5)$ & \\
\hline Gangrenous & $4(2.2)$ & $1(12.5)$ & \\
\hline Perforated & $1(0.55)$ & $1(12.5)$ & \\
\hline Endometriosis & $1(0.55)$ & 0 & \\
\hline Carcinoid & $2(1.1)$ & 0 & \\
\hline Chronic appendicitis & $10(5.5)$ & 0 & \\
\hline Granulomatous & $2(1.1)$ & 0 & \\
\hline Abortion & 0 & 0 & \\
\hline 30-day mortality & 0 & 0 & \\
\hline
\end{tabular}

${ }^{a}$ Pearson's chi-square test. SD: standard deviation; ASA score: American Society of Anesthesiologists score; CRP: C-reactive protein.

by chorioamnionitis and miscarriage at 20 weeks of gestation and two patients by right iliac fossa abscesses requiring percutaneous radiological drainage, in which one of these women delivered a healthy term baby, and the other had chorioamnionitis and preterm delivery at 34 weeks, followed by neonatal death [34]. Nonetheless, early treatment improves maternal and fetal outcomes, with the average time between diagnosis and operation times less than 48 hours $[11,29]$. A study from China to see the association between antibiotics and complication rate among 54 pregnant 
TABLE 2: Rate of complicated appendicitis based on trimester.

\begin{tabular}{lcc}
\hline Pregnancy in weeks & Noncomplicated $(n=6)$ & Complicated $(n=2)$ \\
\hline 6 & 1 & 0 \\
8 & 1 & 0 \\
10 & 1 & 0 \\
13 & 1 & 0 \\
17 & 1 & 0 \\
24 & 1 & 0 \\
26 & 0 & 1 \\
27 & 0 & 1 \\
\hline
\end{tabular}

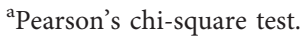

women showed that the patients with antibiotics $(n=34)$ experienced no complications. However, recurrence occurred in the conservative group in one patient during pregnancy and two patients after delivery, treated with appendectomy [35]. In our data, complicated appendicitis was $25 \%$ in pregnant vs. $9 \%$ in nonpregnant women. The majority had suppurative appendicitis and tended to have more fecolith by $75 \%$ vs. $28 \%(p=0.011)$ - the conservative approach not implemented to our patients. The explanation for using antibiotics alone in some centers is that up to onethird of the patients can have a normal appendix. On the contrary, two-thirds can have appendiceal inflammation and one-fourth with abscess [10, 13, 18, 23, 26, 27, 31, 32].

Prolonged exposure to anesthesia can have an adverse effect. The mean operating time of LA is 45 minutes (range: $10-70$ minutes) $[17,18,27,32,35,36]$. In our data, the average time did not differ in the two groups, with a mean of 50 minutes. LA showed significantly shorter operation time, hospital stay, and earlier recovery of gastrointestinal function when compared with the OA group $[8,20]$. In complicated appendicitis, the laparoscopic approach is safe in pregnancy [20]. The hospital stays in the LA group are significantly shorter, with a mean of 2.7 days (ranged 1.5-11 days) $[17,19,21,25,29,32]$. Some favored LA in the first and second trimesters and $\mathrm{OA}$ in the third trimester, where the last trimester patients had double the fold of readmission [21].

A meta-analysis in 2018 and 2021 decided that the laparoscopic approach had a higher rate of fetal demise before 2010 [37, 38]. A study in 1999 of 700 patients showed that rates of fetal losses were $30 \%$ and $10 \%$ in the first and second trimesters, respectively [7]. A systematic review of 637 patients from 1990 to 2017 revealed 6\% fetal losses in the laparoscopic procedure [39]. In our results, we had no infant or maternal mortality in both LA and OA groups. Similarly, there have been no deaths $[8,17,18,31,32]$. On the contrary, a meta-analysis of 17 observational studies showed that LA had a higher risk of fetal loss $(5.69 \%$ vs. $3.73 \%)$ but a low preterm delivery (2.84\% vs. $8.99 \%$ ) [40]. Nearly one out of twenty women who underwent appendectomy can have a complicated obstetrics course in the form of preterm labor, cervical incompetence, vaginal infection, and sepsis [41]. In the last trimester of pregnancy, laparoscopic surgery is feasible and safe with acceptable risk to the fetus and mother $[42,43]$. During pregnancy, the altered immune system makes the patient amenable to disseminating infection. The laparoscopic approach had decreased prevalence of wound infection when compared to open $[37,38]$. Wound infection occurs in $15 \%$ of the patients who underwent appendectomy during cesarean section $[10,13,28,36]$.

The limitation of the study is a retrospective review and a low sample size of the pregnant group.

\section{Conclusions}

Appendectomy during pregnancy carries a low risk regarding fetal abortion or mortality-no significant difference between the pregnant and nonpregnant group concerning appendix perforation, delayed diagnosis, or complications. More evidence is obliged to investigate the advantages of conservative management, such as antibiotics, for acute appendicitis during pregnancy.

\section{Data Availability}

The data used to support the findings of this study are available upon request from the corresponding author Dr. Abdulrahman Alotaibi, Department of Surgery, Faculty of Medicine, University of Jeddah, Saudi Arabia (e-mail: aalotaibi@uj.edu.sa).

\section{Conflicts of Interest}

The authors declare that there are no conflicts of interest regarding the publication of this paper.

\section{References}

[1] R. Kozan, H. Bayhan, Y. Soykan, A. Z. Anadol, M. Sare, and A. B. Aytac, "Acute appendicitis in pregnancy: how to manage?" SiSli Etfal Hastanesi Tip Bulteni/The Medical Bulletin of Sisli Hospital, vol. 54, no. 4, pp. 457-462, 2020.

[2] M. Frountzas, C. Nikolaou, K. Stergios, K. Kontzoglou, K. Toutouzas, and V. Pergialiotis, "Is the laparoscopic approach a safe choice for the management of acute appendicitis in pregnant women? A meta-analysis of observational studies," Annals of the Royal College of Surgeons of England, vol. 101, no. 4, pp. 235-248, 2019.

[3] A. Tase, M. F. A. Kamarizan, and K. Swarnkar, "Appendicitis in pregnancy: difficulties in diagnosis and management. Guidance for the emergency general surgeon: a systematic 
review," International Journal of Surgery Open, vol. 6, pp. 5-11, 2017.

[4] A. H. d. Franca Neto, M. M. R. d. Amorim, and B. M. S. V. Nóbrega, "Acute appendicitis in pregnancy: literature review," Revista da Associação Médica Brasileira, vol. 61, no. 2, pp. 170-177, 2017.

[5] L. Aggenbach, G. G. Zeeman, A. E. P. Cantineau, S. J. Gordijn, and H. S. Hofker, "Impact of appendicitis during pregnancy: No delay in accurate diagnosis and treatment," International Journal of Surgery, vol. 15, pp. 84-89, 2015.

[6] R. Lebeau, B. Diané, E. Koffi, E. Bohoussou, A. Kouamé, and Y. Doumbia, "Appendicite aiguë et grossesse," Journal de Gynécologie Obstétrique et Biologie de la Reproduction, vol. 34, no. 6, pp. 600-605, 2005.

[7] B. Andersen and T. Nielsen, "Appendicitis in pregnancy, Diagnosis, management and complications," Acta Obstetricia et Gynecologica Scandinavica, vol. 78, no. 9, pp. 758-762, 1999.

[8] A. Maimaiti, A. Aierkin, K. M. Mahmood et al., "Laparoscopic appendectomy in pregnancy with acute appendicitis: single center experience with world review," Surgical Laparoscopy Endoscopy \& Percutaneous Techniques, vol. 27, no. 6, pp. 460-464, 2017.

[9] J. Q. Gentles, G. Meglei, L. Chen, C. J. Hague, and A. L. Melck, "Is neutrophilia the key to diagnosing appendicitis in pregnancy?" The American Journal of Surgery, vol. 219, no. 5, pp. 855-859, 2020.

[10] S. F. Kazim and K. M. Inam Pal, "Appendicitis in pregnancy: experience of thirty-eight patients diagnosed and managed at a tertiary care hospital in Karachi," International Journal of Surgery, vol. 7, no. 4, pp. 365-367, 2009.

[11] M. A. El, O. Kaabia, Z. B. Mefteh et al., "Acute appendicitis complicating pregnancy: a 33 case series, diagnosis and management features, maternal and neonatal outcomes," Pan African Medical Journal, vol. 30, p. 212, 2018.

[12] C. Koc, S. Akbulut, E. I. Coşkun, B. Sarıcı, and S. Yılmaz, "Comparison of demographic and clinical features of pregnant and non-pregnant patients undergoing appendectomy," Turkish Journal of Trauma and Emergency Surgery, vol. 26, no. 4, pp. 555-562, 2020.

[13] R. E. Andersson and M. Lambe, "Incidence of appendicitis during pregnancy," International Journal of Epidemiology, vol. 30, no. 6, pp. 1281-1285, 2001.

[14] P. Lemieux, P. Rheaume, I. Levesque, E. Bujold, and G. Brochu, "Laparoscopic appendectomy in pregnant patients: a review of 45 cases," Surgical Endoscopy, vol. 23, no. 8, pp. 1701-1705, 2009.

[15] G. Vasileiou, A. I. Eid, S. Qian et al., "Appendicitis in pregnancy: a post-hoc analysis of an EAST multicenter study," Surgical Infections, vol. 21, no. 3, pp. 205-211, 2020.

[16] M. T. Silvestri, C. M. Pettker, E. C. Brousseau, M. A. Dick, M. M. Ciarleglio, and E. A. Erekson, "Morbidity of appendectomy and cholecystectomy in pregnant and nonpregnant women," Obstetrics \& Gynecology, vol. 118, no. 6, pp. 1261-1270, 2011.

[17] J.-S. Jeong, D. H. Ryu, H. Y. Yun, E.-H. Jeong, J.-W. Choi, and L.-C. Jang, "Laparoscopic appendectomy is a safe and beneficial procedure in pregnant women," Surgical Laparoscopy Endoscopy \& Percutaneous Techniques, vol. 21, no. 1, pp. 24-27, 2011.

[18] S. H. Park, M. I. Park, J. S. Choi, J. H. Lee, H. O. Kim, and H. Kim, "Laparoscopic appendectomy performed during pregnancy by gynecological laparoscopists," European Journal of Obstetrics \& Gynecology and Reproductive Biology, vol. 148, no. 1, pp. 44-48, 2010.

[19] A. Türkan, M. Yalaza, M. T. Kafadar, and G. Değirmencioğlu, "Acute appendicitis in pregnant women: our clinical experience," Clinical and investigative medicine. Medecine clinique et experimentale, vol. 39, no. 6, p. 27521, 2016.

[20] T. C. Cox, C. R. Huntington, L. J. Blair et al., "Laparoscopic appendectomy and cholecystectomy versus open: a study in 1999 pregnant patients," Surgical Endoscopy, vol. 30, no. 2, pp. 593-602, 2016.

[21] A. Tumati, J. Yang, X. Zhang et al., "Pregnant patients requiring appendectomy: comparison between open and laparoscopic approaches in NY State," Surgical Endoscopy, vol. 35, no. 8, pp. 4681-4690, 2021.

[22] F. Tatli, Y. Yucel, O. Gozeneli et al., "The Alvarado Score is accurate in pregnancy: a retrospective case-control study," European Journal of Trauma and Emergency Surgery, vol. 45, no. 3, pp. 411-416, 2019.

[23] B. Burcu, O. Ekinci, and T. Atak, "Acute appendicitis in pregnancy: case series and review," Northern Clinics of Istanbul, vol. 3, no. 1, pp. 60-63, 2015.

[24] N. Miloudi, M. Brahem, S. Ben Abid, Z. Mzoughi, N. Arfa, and M. Tahar Khalfallah, "Acute appendicitis in pregnancy: specific features of diagnosis and treatment," Journal of Visceral Surgery, vol. 149, no. 4, pp. e275-e279, 2012.

[25] K. C. Yoo, J. H. Park, K. H. Pak et al., "Could laparoscopic appendectomy in pregnant women affect obstetric outcomes? A multicenter study," International Journal of Colorectal Disease, vol. 31, no. 8, pp. 1475-1481, 2016.

[26] Y. Peled, L. Hiersch, O. Khalpari, A. Wiznitzer, Y. Yogev, and J. Pardo, "Appendectomy during pregnancy - is pregnancy outcome depending by operation technique?" Journal of Maternal-Fetal and Neonatal Medicine, vol. 27, no. 4, pp. 365-367, 2014.

[27] N. Halkic, A. A. Tempia-Caliera, R. Ksontini, M. Suter, J.-F. Delaloye, and H. Vuilleumier, "Laparoscopic management of appendicitis and symptomatic cholelithiasis during pregnancy," Langenbeck's Archives of Surgery, vol. 391, no. 5, pp. 467-471, 2006.

[28] L. Segev, Y. Segev, S. Rayman, A. Nissan, and E. Sadot, “Acute appendicitis during pregnancy: different from the nonpregnant state?" World Journal of Surgery, vol. 41, no. 1, pp. 75-81, 2017.

[29] M. Nakashima, M. Takeuchi, and K. Kawakami, "Clinical outcomes of acute appendicitis during pregnancy: conservative management and appendectomy," World Journal of Surgery, vol. 45, no. 6, pp. 1717-1724, 2021.

[30] J. Tankel, S. Yellinek, Y. Shechter et al., "Delaying laparoscopic surgery in pregnant patients with an equivocal acute appendicitis: a step-wise approach does not affect maternal or fetal safety," Surgical Endoscopy, vol. 33, no. 9, pp. 2960-2966, 2019.

[31] C. Moreno-Sanz, A. Pascual-Pedreño, J. S. Picazo-Yeste, and J. B. Seoane-Gonzalez, "Laparoscopic appendectomy during pregnancy: between personal experiences and scientific evidence," Journal of the American College of Surgeons, vol. 205, no. 1, pp. 37-42, 2007.

[32] J. F. Laustsen, O. S. Bjerring, Ø Johannessen, and N. Qvist, "Laparoscopic appendectomy during pregnancy is safe for both the mother and the fetus," Danish medical journal, vol. 63 , no. 8, p. 5259, 2016.

[33] M. A. de Moya, A. C. Sideris, G. Choy et al., "Appendectomy and pregnancy: gestational age does not affect the position of 
the incision," The American Surgeon, vol. 81, no. 3, pp. 282-288, 2015.

[34] S. Guterman, L. Mandelbrot, H. Keita, F. Bretagnol, D. Calabrese, and S. Msika, "Laparoscopy in the second and third trimesters of pregnancy for abdominal surgical emergencies," Journal of Gynecology Obstetrics and Human Reproduction, vol. 46, no. 5, pp. 417-422, 2017.

[35] J. Liu, M. Ahmad, J. Wu et al., "Antibiotic is a safe and feasible option for uncomplicated appendicitis in pregnancy - A retrospective cohort study," Asian Journal of Endoscopic Surgery, vol. 14, no. 2, pp. 207-212, 2021.

[36] M. Kulhan, N. G. Kulhan, U. Nayki et al., "Outcomes of the patients diagnosed incidentally appendicitis during cesarean section," Ginekologia Polska, vol. 88, no. 3, pp. 147-150, 2017.

[37] Q. Zeng, A. Aierken, S.-S. Gu et al., "Laparoscopic versus open appendectomy for appendicitis in pregnancy: systematic review and meta-analysis," Surgical Laparoscopy Endoscopy \& Percutaneous Techniques, vol. 31, no. 5, pp. 637-644, 2021.

[38] A. Prodromidou, N. Machairas, I. D. Kostakis et al., "Outcomes after open and laparoscopic appendectomy during pregnancy: a meta-analysis," European Journal of Obstetrics \& Gynecology and Reproductive Biology, vol. 225, pp. 40-50, 2018.

[39] C. A. Walsh, T. Tang, and S. R. Walsh, "Laparoscopic versus open appendicectomy in pregnancy: a systematic review," International Journal of Surgery, vol. 6, no. 4, pp. 339-344, 2008.

[40] J. Chakraborty, J. C. Kong, W. K. Su et al., "Safety of laparoscopic appendicectomy during pregnancy: a systematic review and meta-analysis," ANZ Journal of Surgery, vol. 89, no. 11, pp. 1373-1378, 2019.

[41] A. Sachs, J. Guglielminotti, R. Miller, R. Landau, R. Smiley, and G. Li, "Risk factors and risk stratification for adverse obstetrical outcomes after appendectomy or cholecystectomy during pregnancy," JAMA Surgery, vol. 152, no. 5, pp. 436-441, 2017.

[42] A. Upadhyay, S. Stanten, G. Kazantsev, R. Horoupian, and A. Stanten, "Laparoscopic management of a nonobstetric emergency in the third trimester of pregnancy," Surgical Endoscopy, vol. 21, no. 8, pp. 1344-1348, 2007.

[43] J. K. de Bakker, L. M. Dijksman, and S. C. Donkervoort, "Safety and outcome of general surgical open and laparoscopic procedures during pregnancy," Surgical Endoscopy, vol. 25, no. 5, pp. 1574-1578, 2011. 